\title{
ANALISIS TINGKAT KEPUASAN PELANGGAN JASA INTERNET
}

\author{
Oleh: \\ Joko Samboro *)
}

\begin{abstract}
This research analisys to find out the degree of customers' satisfaction and to give informations to the management to direct customers' need in order to achieve customers' satisfactioan. To collect the data, the purposive sampling is applied in this research 90 guestionaires are distributed togo respondents and then they are analyzed by using the window of satisfaction on the cartecius diagram

The result of the research indicates that mostof the cuatomers are not satisfied, the degree of their satisfactions is less than 100\%. Further, some service items available in the firm are stiil low. The researcher hopes the result of this research is able to give the informa tion to the firm's leader in finding out the effective strategy in geeting more customers.
\end{abstract}

Keywords : costomers, satisfaction.

\section{PENDAHULUAN}

\section{Latar Belakang}

Perkembangan jasa internet dewasa ini semakin pesat seiring dengan kemajuan dalam bidang komputerisasi dan telekomunikasi. Dengan teknologi ini, dunia menjadi semakin sempit, dan batas hubungan antar negara semakin dekat. Kehadiran internet disamping menyediakan berbagai kemudahan nampaknya tidak hanya digunakan dalam rangka mendapatkan informasi untuk kegiatan politik dan pendidikan, tetapi juga untuk kegiatan bisnis. Dengan berkembangnya fungsi internet sebagai sarana informasi, maka berkembang pula para pengguna jasa internet.

Sehubungan dengan perkembangan internet maka kebutuhan penyedia jasa internet juga berkembang. Internet yang semula terdapat di kantor-kantor dan lembaga pendidikan, sekarang penyedia jasa persewaan internet tidak terbatas hanya lembaga lembaga tersebut. Didalam memberikan kualitas jasa pelayanan yang baik kepada pelanggan, terdapat lima kriteria penentu kualitas jasa pelayanan yaitu : Tangibles (bukti fisik), reliability (keandalan), responsiveness (ketanggapan), assurance (jaminan) dan empathy ( Parasuraman dalam Rambat, 2001:148).

Pada dasarnya kepuasan pelanggan merupakan perbedaan antara harapan dengan kinerja atau kualitas pelayanan perusahaan, ketika kualitas pelayanan tidak sesuai dengan harapanya, maka ia merasa tidak puas (Kotler,1998:188). Pelanggan yang puas, 
mereka akan cenderung mengulang perilaku yang memberikan kepuasan. Jika pelanggan orangnya "ramai", maka ia akan mempromosikan kehebatan produk tersebut, dan ini merupakan iklan yang gratis bagi perusahaan.

Kepuasan pelanggan menjadi penting artinya bagi perusahaan, karena kepuasan pelanggan akan berpengaruh terhadap : tingkat pengembangan laba, mencerminkan tingkat keberhasilan menejemen, menggambarkan keberhasilan/kegagalan dalam mendapatkan dan mempertahankan pelanggan dan menjadi umpan balik sebagai wujud pertanggung-jawaban ke pemilik atau pemegang saham. Demikian juga perusahaan jasa internet, dimana jasa yang ditawarkan menghadapi persaingan yang sangat tajam, sehingga menejemen dituntut untuk mengelola kualitas pelayanan yang baik, agar kepuasan konsumen dapat terpenuhi.

\section{Rumusan masalah}

Bagaimana tingkat kepuasan pelanggan jasa internet

\section{Tujuan Penelitian.}

Tujuan penelitian ini untuk mengetahui sejauh mana tingkat kepuasan pelanggan.

\section{KAJIAN PUSTAKA}

\section{Penelitian Empirik}

Terdapat beberapa penelitian terdahulu yang dapat dikemukakan disini antara lain:

a.Parasuraman,Zeithaml dan Berry (1988). Dalam journal of Marketing dengan judul: "Serqual A Multiple-Item Scale for Measuring Consumer Perceptions of Service Quality “, dengan menggunakan lima dimensi yaitu : tangibles, responsiveness, reliability, assurance dan imphaty yang berpengaruh terhadap kepuasan pada perusahaan Bank, Perusahaan Kartu Kredit dan Perusahaan Perbaikan dan Pemeliharaan serta Perusahaan Telepon.

b.Cronin \& Tailor (1993), mereka menyatakan bahwa daya tanggap (Responsiveness) merupakan salah satu faktor atau variabel bebas yang dapat mempengaruhi kepuasan pelanggan pada industri jasa (hotel, perbankan, dan perusahaan fast food). 
Taylor menguji berbagai cara terbaik dalam mengukur tingkat kualitas jasa dan menyimpulkan bahwa cara terbaik dalam mengukur kualitas jasa adalah cengan cara mengukur persepsi pelanggan terhadap kinerja perusahaan.

c.Pujawan (1997). melakukan penelitian pada responden suatu Bank dan dimana dimen si reliability (kehandalan) menempati pada urutan pertama dalam menilai kepuasan nasabah/pelanggan.

\section{Pengertian Jasa.}

Jasa adalah kegiatan atau manfaat yang ditawarkan oleh satu pihak kepada pihak lain yang pada dasarnya tanpa wujud dan tidak menghasilkan kepemilikan apapun. (Rismiati,2001:270), misalnya aktivitas menyewakan komputer.

\section{Karakteristik Jasa.}

Setiap perusahaan harus memperhatikan empat karakteriatik jasa, ketika merancang program pemasaranya, yaitu : sifat tak berwujud (intangibility), tak terpisahkan (inseparability), keanekaragaman (variability)dan tak tahan lama (perishability). (Rismiati,2001:272).Jasa tidak dapat dilihat, dicecap, dirasakan, didengar atau dicium sebelum dibeli. Mutu jasa tergantung pada orang yang menyediakan jasa dan waktu, tempat dan cara mereka menyediakan.Jasa tak dapat dipisahkan dari penyedianya. Dan jasa tidak dapat disimpan untuk dijual atau dipakai kemudian.

\section{Kualitas Pelayanan.}

Suatu cara perusahaan jasa untuk tetap dapat unggul bersaing adalah dengan memberikan jasa dengan kualitas yang lebih tinggi dari pesainganya secara konsisten. Indikasi kualitas pelayanan yaitu : Tangibles (bukti fisik), reliability (keandalan), responsiveness (ketanggapan), assurance (jaminan) dan empathy ( Parasuraman dalam Rambat, 2001:148) Bukti fisik adalah aspek nyata yang dapat dilihat dan diraba.Keandalan adalah kemampuan untuk membuktikan janji pelayanan secara akurat. Ketanggapan merupakan kemauan untuk membantu konsumen dan menyediakan pelayanan. Jaminan merupakan keyakinan, pengetahuan dan kepercayaan diri karyawan untuk membangun kepercayaan dari konsumen. Sedangkan impati merupakan perhatian pribadi kepada konsumen.

\section{Pengertian Kepuasan.}


Kepuasan adalah tingkat perasaan seseorang setelah membandingkan antara persepsi atas kinerja suatu perusahaan dengan harapan para pelanggan. (http://www.geocities.com).

Pendapat Schnars dalam Fandy Tjiptono (1996), mengatakan bahwa pada dasarnya tujuan dari suatu bisnis adalah untuk menciptakan para pelanggan yang merasa puas. Terciptanya kepuasan pelanggan akan memberikan beberapa manfaat, antara lain hubungan antara perusahaan dan pelanggan menjadi harmonis, memberikan dasar yang baik bagi pembelian ulang dan terciptanya loyalitas pelanggan.

Pendapat Wilkie tentang kepuasan sebagai suatu tanggapan emosional pada evaluasi terhadap pengalaman konsumsi suatu produk atau jasa Tjiptono (1996). Selanjutnya Engel (1995) berpendapat bahwa kepuasan pelanggan merupakan evaluasi purnabeli dimana alternative yang dipilihnya sekurang-kurangnya sama atau melampaui harapan pelanggan. Sedangkan ketidakpuasan timbul apabila hasil (outcome) tidak memenuhi harapan. Sedangkan Kotler (1997) menandaskan bahwa, kepuaan pelanggan adalah tingkat perasaan seseorang setelah membandingkan kinerja yang ia rasakan dengan harapannya.

Berdasarkan temuan Tse dan Wilton (1998) kepuasan pelanggan dirumuskan sebagai berikut:

$$
\text { Kepuasan Pelanggan }=\mathrm{f}(\text { performance }- \text { expectation })
$$

Dari persamaan tersebut dapat diketahui bahwa :

Pertama: Performance < Expectation

Bila hal ini terjadi, maka pelanggan mengatakan bahwa pelayanan yang diberikan jelek, karena harapan pelanggan tidak terpenuhi atau pelayanan kurang baik, belum memuaskan pelanggan.

Kedua : Performance $=$ Expectation

Bila keadaan ini terjadi, maka pelanggan tidak ada istimewanya, pelayanan yang diberikan biasa-biasa saja, karena belum memuaskan pelanggan.

Ketiga : Performance $>$ Expectation

Bila keadaan ini tercapai, maka pelanggan mengatakan pelayanan yang diberikan adalah baik dan menyenangkan. 
Untuk mengevaluasi kinerja perusahaan digunakan diagram kartesius yaitu berupa jendela kepuasan dimana terdapat kuadran yang dapat menggambarkan dan membandingkan antara harapan konsumen dengan kinerja perusahaan.

Menurut Husein Umar (2000:451) “ Diagram Kartesius yang berupa jendela kepuasan adalah suatu bangunan yang terdiri atas empat bagian yang di batasi oleh dua garis yang perpotongan tegak lurus pada titik $X$ dan $Y$ ". Dengan diagram ini akan didapatkan hasil yang jelas mengenai tingkat kepuasan konsumen. Diagram Kartesius dibagi empat kuadran seperti gambar dibawah ini:

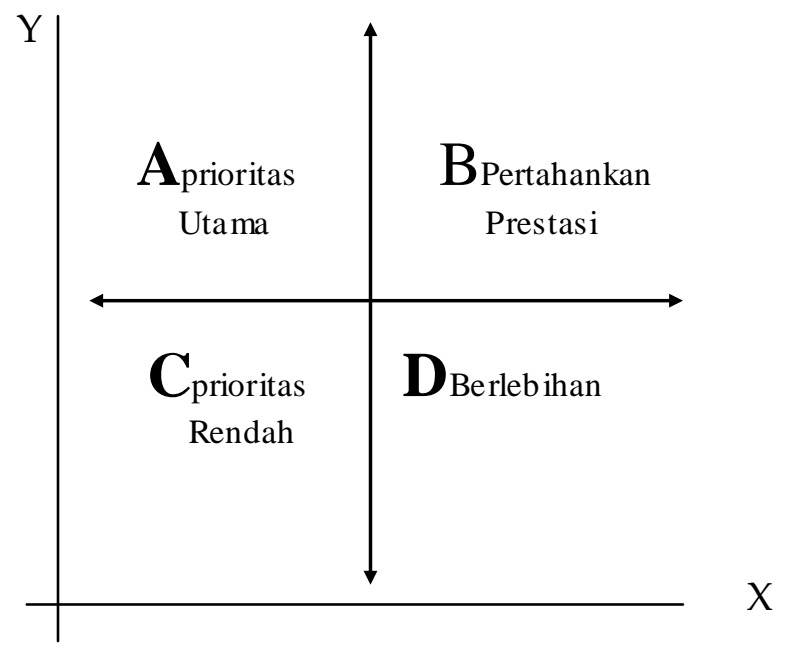

Gambar : 1 Diagram Kartesius

Sumber: Vincent Gaspersz (1997:75).

Kuadran A : Kinerja suatu variabel adalah lebih rendah dari keinginan pelanggan sehingga perusahaan harus meningkatkan kinerjanya agar optimal.

Kuadran B : Kinerja dan keinginan pelanggan pada suatu variabel berada pada tingkat tinggi dan sesuai, sehingga perusahaan cukup mempertahankan kinerja variable tersebut.

Kuadran C : Kinerja dan keinginan pelanggan pada suatu variabel berada pada tingkat rendah, sehingga perusahaan belum perlu melakukan perbaikan.

Kuadaran D : Kenerja perusahaan berada dalam tingkat tinggi tetapi keinginan pelanggan akan kinerja dari variabel tersebut hanya rendah, sehingga perusahaan perlu mengurangi hasil yang dicapai agar dapat mengefisienkan sumberdaya perusahaan.

\section{Mempertahankan Pelanggan.}


Membicarakan pelanggan berarti kita harus memenuhi tuntutanya sesuai standart kualitas tertentu,karenanya akan memberikan pengaruh kepada performance kita.

Pelanggan, menurut Vincent Gaspersz adalah orang yang tidak tergantung pada kita, tetapi kita yang tergantung pada dia, pelanggan adalah orang yang membawa kita kepada keinginannya, tidak seorangpun yang pernah menang beradu argumentasi dengan pelanggan dan pelanggan adalah orang yang teramat penting yang harus dipuaskan (Gaspersz, 1997:73). Jadi pelanggan harus dipuaskan dengan system kualitas modern.

Dengan ketatnya persaingan, maka perusahaan perlu mempertahankan pelanggan antara lain dengan memberikan manfaat keuangan, manfaat sosial dan ikatan struktural. (Kotler,1998:196). Manfaat keuangan misalnya, memberikan potongan harga, hotel memberikan kamar dengan standart yang lebih tinggi kepada pelangganya. Manfaat sosial seperti, menyapa tamu dengan namanya dan ikatan struktural memberikan fasilitas layanan langsung kepada atasanya, sehingga pelanggan merasa puas dan tidak beralih ke pesaing.

\section{Kerangka Konseptual}

Kerangka konseptual yamg merupakan frame work dalam penyususnan model, dapat disampaikan melalui gambar dibawah ini :

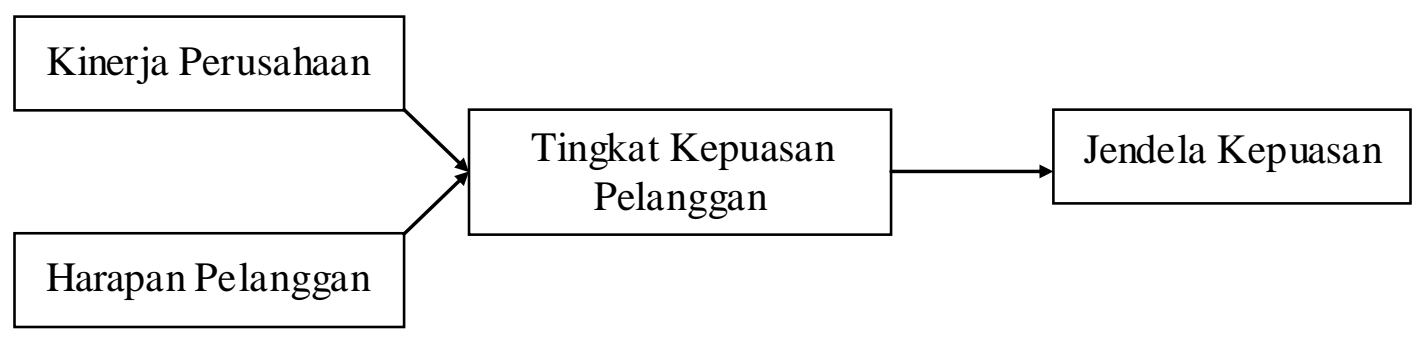

Gambar : 1 Kerangka Konseptual

Seberapa besar kinerja perusahaan yang diukur dengan Tangibles (bukti fisik), reliability (keandalan), responsiveness (ketanggapan), assurance (jaminan) dan empathy dibandingkan dengan harapan pelanggan, maka akan didapat tingkat kepuasan pelanggan. Bagaimana perusahaan dapat menyikapinya, maka diperlukan analisis diagram melalui jendela kepuasan. 


\section{METODE PENELITIAN}

Objek kajian ini adalah semua pelanggan jasa internet di Kota Malang, dengan teknik penarikan sampel berdasarkan porposive sampling. Pemilihan metode ini atas dasar pertimbangan/tujuan tertentu yang dimungkinkan tercapainya tujuan penelitian (Indriantoro : 1999, 131). Diperoleh 90 responden pelanggan jasa internet, baik yang menggunakan jasa pada tempat yang strategis (di jalan Merdeka Selatan) maupun dekat dengan dunia pendidikan (Di jalan MT.Haryono, jalan. Sumbersari ,jalan Veteran dan jalan Dieng)

Teknik pengukuranya menggunakan skala likert, dimana responden menyatakan tingkat sangat baik atau tidak baik dari berbagai pertanyaan mengenai perilaku obyek, orang atau kejadian (Kuncoro,2003:157) dengan :

Jawaban a : sangat baik : diberi skor 5 Jawaban a: sangat puas : diberi skor 5

Jawaban $\mathrm{b}$ : baik : diberi skor 4 Jawaban $\mathrm{b}$ : puas $\quad$ : diberi skor 4 Jawaban c : biasa saja/netral : diberi skor 3 Jawaban c : biasa saja/netral : diberi skor 3

Jawaban d : kurang baik : diberi skor 2 Jawaban $\mathrm{d}$ : kurang puas : diberi skor 2 Jawaban e : tidak baik : diberi skor 1 Jawaban e : tidak puas : diberi skor 1 Jawaban a sampai e dimaksudkan untuk memperoleh data kuantitatif yang akan dianalisis lebih lanjut.

\section{Definisi Operasional.}

Variabel Kualitas Pelayanan dan harapan pelanggan , dengan indikator a.Tangibles (bukti fisik), dengan item: (1).Peralatan dan perlengkapan komputer yang memadai dan baik.(2).Akses komputer cepat dan tepat.(3).Ruangan komputer yang memadai dan nyaman.(4).Penataan sekat komputer yang rapi.(5).Kelengkapan dan kemudahan jasa internet (email, home page dll).(6).Tempat parkir yang memadai dan aman.(7).Kebersihan gedung.(8).Kebersihan dan kerapian pegawai.

b.Reliability (keandalan) dengan item: (9).Kesigapan pegawai dalam memberikan pelayanan.(10).Ketelitian pegawai dalam memberikan pelayanan.(11).Prosedur Pelayanan yang cepat dan tepat.(12).Pelayanan yang ramah dan tepat

c.Responsiveness (ketanggapan) dengan item : (13).Kemampuan pegawai untuk cepat tanggap dalam menangani keluhan pada saat dibutuhkan oleh pelanggan.(14). 
Kemampuan pegawai untuk cepat tanggap dalam menangani masalah yang terjadi.(15). Kemampuan pegawai untuk dalam memberikan informasi yang jelas dan mudah dimengerti.

d.Assurance (jaminan) dengan item : (16).Pelayanan yang sopan dan ramah.(17).Mampu berkomunikasi dengan baik dalam memberikan pelayanan.(18).Kemampuan dan pengetahuan pegawai dalam bidang internet.(19).Kemudahan mendapatkan informasi. (20).Jaminan keamanan dalam menggunakan jasa.

e.Empathy atau X5, dengan item : (21).Perhatian kepada setiap pelanggan.(22).Perhatian terhadap keluhan pelanggan.(23).Memberikan kesesuaian jam kerja dengan kesibukan pelanggan.

\section{Metode Analisis}

Didalam pengukuran tingkat kepuasan konsumen digunakan rumus yaitu :

$$
\mathrm{Tki}=\frac{\mathrm{Xi}}{\mathrm{Yi}} \times 100 \%
$$

Tki : Tingkat kepuasan pelanggan

$\mathrm{Xi}$ :Skor penilaian kinerja perusahaan

Yi : Skor penilaian harapan pelanggan. (Supranto : 1997,241).

Untuk mengevaluasi kinerja perusahaan dipergunakan diagram kartesius berupa jendela kepuasan

\section{HASIL DAN PEMBAHASAN}

\section{Hasil Penelitian}

Dari 90 kuisner yang dibagikan kepada responden kemudian ditabulasi, seperti tampak pada tabel: 1 dibawah ini 


\begin{tabular}{|c|c|c|c|c|c|}
\hline VARIABEL & $\begin{array}{c}\text { KINERJA } \\
\text { (Xi) }\end{array}$ & $\begin{array}{c}\text { HARAPAN } \\
\text { (Yi) }\end{array}$ & $\bar{X}$ & $\overline{\mathrm{Y}}$ & Tki \\
\hline \multicolumn{6}{|l|}{ a.Tangibles } \\
\hline 1 & 296 & 400 & 3,288 & 4,444 & 74 \\
\hline 2 & 262 & 415 & 2,911 & 4,611 & 64 \\
\hline 3 & 301 & 377 & 3,344 & 4,183 & 80 \\
\hline 4 & 317 & 372 & 3,522 & 4,133 & 85 \\
\hline 5 & 312 & 412 & 3,466 & 4,577 & 76 \\
\hline 6 & 266 & 384 & 2,955 & 4,266 & 68 \\
\hline 7 & 331 & 363 & 3,677 & 4,033 & 91 \\
\hline $\begin{array}{l}8 \\
\text { b. Reliability }\end{array}$ & 328 & 331 & 3,644 & 3,677 & 99 \\
\hline 9. & 342 & 388 & 3,800 & 4,311 & 88 \\
\hline 10. & 399 & 377 & 3,322 & 4,188 & 79 \\
\hline 11. & 304 & 381 & 3,800 & 4,233 & 79 \\
\hline $\begin{array}{l}12 . \\
\text { cResponsiveness }\end{array}$ & 309 & 274 & 3,433 & 3,044 & 112,7 \\
\hline 13. & 312 & 388 & 3,466 & 4,311 & 80 \\
\hline 14. & 314 & 396 & 3,488 & 4,400 & 79 \\
\hline $\begin{array}{l}15 . \\
\text { d. Assurance }\end{array}$ & 297 & 379 & 3,300 & 4,211 & 78 \\
\hline 16 & 317 & 371 & 3,522 & 4,122 & 85 \\
\hline 17. & 299 & 367 & 3,300 & 4,077 & 81 \\
\hline 18 & 322 & 396 & 3,577 & 4,400 & 81 \\
\hline $\begin{array}{l}19 \\
\text { e. Empathy }\end{array}$ & 302 & 384 & 3,355 & 4,266 & 78 \\
\hline 20 & 299 & 383 & 3,322 & 4,255 & 78 \\
\hline 21 & 242 & 354 & 2,711 & 3,933 & 82 \\
\hline 22 & 283 & 337 & 3,144 & 4,188 & 83 \\
\hline 23 & 285 & 364 & 3,166 & 4,044 & 78 \\
\hline & & Total & 77,513 & 95,912 & \\
\hline
\end{tabular}

Tabel :1 Rekapitulasi Hasil Kuisner

Sumber: hasil kuisner diolah 
Keterangan:

$$
\begin{aligned}
& \bar{X}: \quad \frac{\sum \text { Kinerja }\left(\mathrm{Xi}_{\mathrm{i}}\right)}{\sum \text { responden }} \\
& \overline{\mathrm{Y}}: \quad \frac{\sum \text { Harapan }(\mathrm{Yi})}{\sum \text { responden }} \\
& \sum \text { responden }=90 \text { orang } \\
& \text { Tki }=\frac{\mathrm{Xi}}{\mathrm{Yi}} \times 100 \%
\end{aligned}
$$

Tki : Tingkat kepuasan pelanggan

Xi : TotalSkor penilaian kinerja perusahaan

$\mathrm{Yi}$ : TotalSkor penilaian harapan pelanggan.

Pada tabel: 1 diatas, tampak bahwa tingkat kepuasan pelanggan masih dibawah $100 \%$ kecuali pada kecuali pada variabel Reliability item ke 12 dengan tingkat kepuasan pelanggan sebesar $112,7 \%$. Ini artinya bahwa secara umum pelanggan jasa internet masih belum puas.

\section{Pembahasan}

Berdasarkan Tabel : 1. diatas ternyata hanya pada variable reliability secara individu pada item 12 dimana kinerja pelayanan yang ramah dan tepat dirasa pelanggan melebihi dari harapanya, sehingga mereka merasa puas. Temuan ini didukung oleh pendapat dimana dimensi reliability menempati urutan pertama dalam menilai kepuasan pelanggan. Tetapi secara serentak keterkaitan semua dimensi akan terlihat kedalam diagram kartesius berupa jendela kepuasan seperti dibawah ini : 


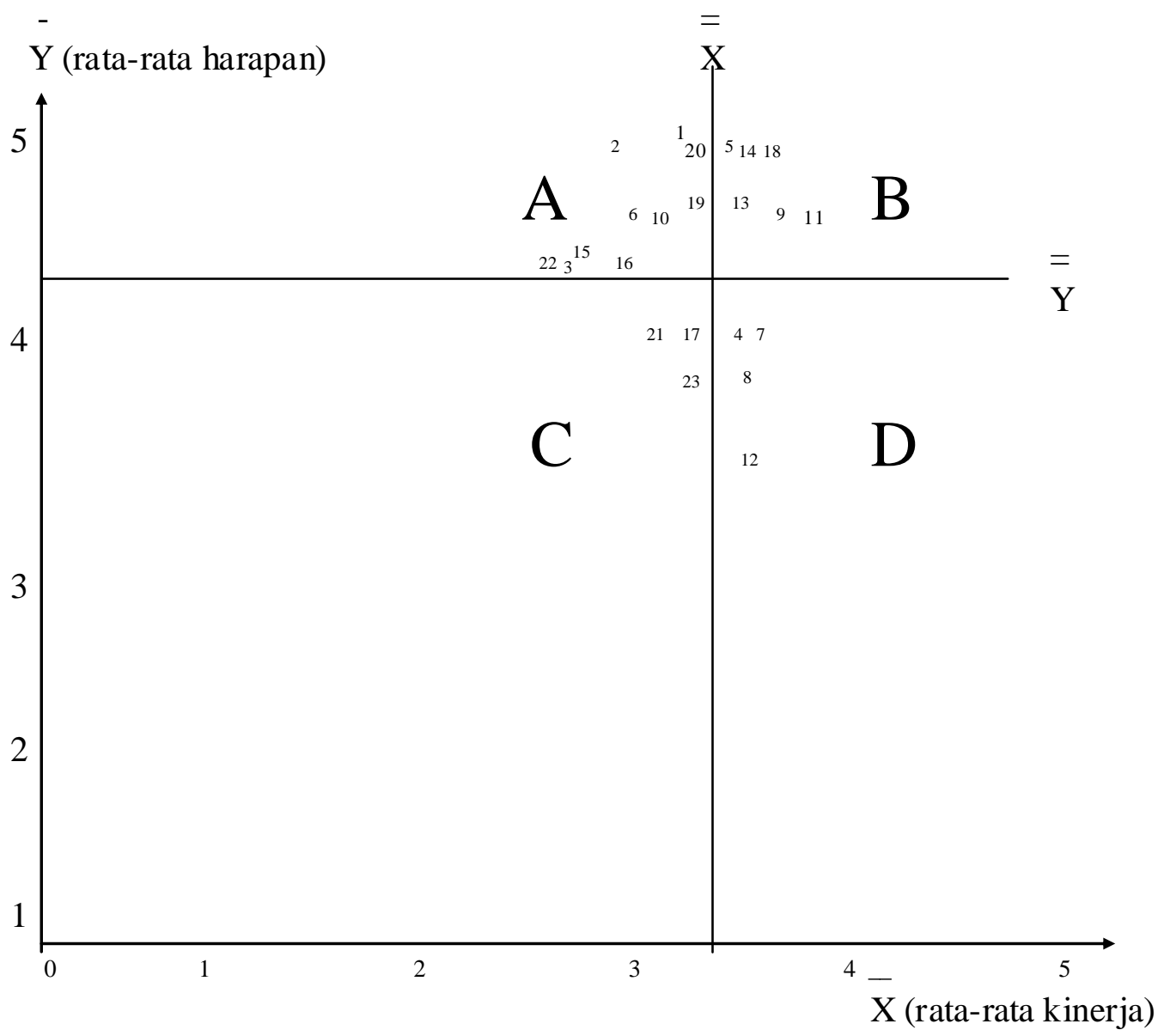

Bagan : 2 Jendela Kepuasan

Keterangan:

$$
\begin{aligned}
\overline{\bar{X}} & =\frac{\text { Total Kinerja }}{\sum \text { Item }} \\
& =\frac{77,513}{23} \\
& =3,37
\end{aligned}
$$

$$
\begin{array}{r}
\overline{\overline{\mathrm{Y}}}=\frac{\text { Total Harapan }}{\sum \text { item }} \\
=\frac{95,912}{23} \\
=4,17
\end{array}
$$

Berdasarkan bagan : 2 , diatas dapat di jelaskan bahwa rata-rata stadard untuk kinerja rata-rata dari $\overline{\bar{X}}=3,37$, sedangkan untuk harapan rata-rata $\overline{\overline{\mathrm{Y}}}=4,17$

\section{Kuadran A}

Kinerja atau pelayanan yang diberikan oleh perusahaan jasa internet, kurang dari rata-rata $\overline{\bar{X}}=3,37$ sedang untuk harapan konsumen diatas rata-rata dari $\overline{\bar{Y}}=4,17$, sehingga konsumen merasa tidak puas atas pelayanan yang diberikan oleh perusahaan, 
dimana item yang berada pada kuadran A ini adalah: (1).Peralatan dan perlengkapan komputer kurang memadahi dan kurang baik seperti tidak adanya video camera, banyaknya perangkat komputer yang rusak. (2).Akses komputer kurang cepat dan kurang tepat, seperti jasa chating yang kurang cepat atau lamban.(3).Ruangan komputer kurang memadahi dan kurang nyaman hal ini dapat dilihat pada ruangan yang terkesan kotor dan tidak adanya tempat sampah di dalam ruangan. (6).Tempat parkir yang memadahi dan nyaman.(10).Ketelitian pegawai dalam memberi pelayanan masih kurang. (15).Kemampuan petugas dalam memberi informasi yang jelas dan.(19). Kemudahan dalam mendapatkan informasi.(20).Jaminan keamanan dalam menggunakan jasa.

Dengan adanya item pada kuadran A ini maka perusahaan jasa internet kurang mampu memberikan pelayanan atau kinerja yang sesuai degan harapan konsumen.

\section{Kuadaran B}

Kinerja yang telah diberikan oleh perusahaan jasa internet melebihi dari $\overline{\bar{X}}=$ 3,37 sedangkan untuk harapan konsumen berada pada tingkat tinggi dan sesuai dengan $\overline{\bar{Y}}=4,17$, sehingga konsumen merasa puas atas pelayanan yang diberikan oleh perusahaan, item yang berada pada kuadran ini adalah: (5).Kelengkapan dan kemudahan jasa internet.(9).Kesigapan pegawai dalam memberi peyalanan.(11).Prosedur pelayanan yang cepat dan tepat, item (9) dan (11) ini didukukung oleh Pujawan sedangkan (13).Kemampuan pegawai untuk cepat tanggap dalam menangani keluhan pada saat di butuhkan oleh pelanggan. dan (14).Kemampuan pegawai untuk cepat tanggap dalam menangani masalah yang terjadi, didukung oleh penelitian yang dilakukan oleh Cronin \& Tailor.(16).Pelayanan yang sopan dan ramah.(18).Kemampuan dan pengetahuan pegawai dalam bidang internet.

Dengan adanya item pada kuadran B ini maka perusahaan jasa internet telah memberikan kinerja yang baik terhadap konsumen, dimana kinerja yang diberikan sesuai dengan harapan konsumen,sehingga prestasi ini perlu dipertahankan.

\section{Kuadran C}

Kinerja yang diberikan oleh perusahaan jasa internet sangat baik yakni melebihi atau diatas rata-rata dari $\overline{\bar{X}}=3,37$ sedangkan harapan konsumen menganggap bahwa 
variabel ini tidak begitu penting atau kurang dari rata-rata $\overline{\bar{Y}}=4,17$, sehingga perusahaan perlu mengurangi hasil yang dicapai agar dapat mengefesienkan sumber daya perusahaan. Item yang berada pada kuadran C ini adalah: (17).Mampu berkomunikasi dengan baik dalam memberikan pelayanan.(21). Memberikan kesesuaian jam kerja dengan kesibukan konsumen.(23). Kesungguhan terhadap kepentingan konsumen.

Perusahaan jasa internet perlu mengurangi kinerja yang diberikan karena konsumen menganggap bahwa item diatas kurang begitu penting.

\section{Kuadran D}

Kinerja dan keinginan konsumen pada suatu variabel berada pada tingkat rendah yaitu untuk kinerja yang diberikan oleh perusahaan jasa internet kurang dari

rata-rata $\overline{\bar{X}}=3,37$ sedangkan harapan konsumen juga kurang dari rata-rata $\overline{\bar{Y}}=4,17$. Item yang berada pada kuadran D ini adalah: (4). Penataan sekat komputer kurang rapi. Sekat komputer hendaknya dibuat berhadapan sehingga kerahasiaan konsumen terjamin.(7).Kebersihan gedung.(8). Kebersihan dan kerapian seragam petugas yang dipakai.(12). Pelayanan yang ramah dan tepat.

Perusahaan jasa internet perlu meningkatkan kinerjanya lagi.

Hasil penelitian ini mendukung penelitian sebelumnya yang dilakukan oleh Parasuraman dan Taylor bahwa teknik yang terbaik dalam mengukur tingkat kualitas jasa adalah dengan mengukur persepsi pelanggan dengan kinerja perusahaan dengan indikator Tangibles (bukti fisik), reliability (keandalan), responsiveness (ketanggapan), assurance (jaminan) dan empathy dan sama dengan penelitian yang dilakukan oleh Pujawan. Dimana variabel yang dominan terhadap kepusan pelanggan terletak pada variabel reliability.

\section{Strategi Peningkatan Kualitas Pelayanan.}

Bertolak dari diagram jendela kepuasan maka strategi yang harus dilakukan oleh perusahaan adalah dengan mempertahankan pada kwadran B yaitu, mempertahankan kelengkapan dan kemudahan jasa internet, kesigapan pegawai dalam memberi peyalanan, prosedur pelayanan yang cepat dan tepat, kemampuan pegawai untuk cepat tanggap dalam menangani keluhan pada saat di butuhkan oleh pelanggan, kemampuan pegawai untuk cepat tanggap dalam menangani masalah yang terjadi, pelayanan yang 
sopan dan ramah dan kemampuan dan pengetahuan pegawai dalam bidang internet serta meningkatkan peralatan dan perlengkapan komputer kurang memadahi dan kurang baik seperti tidak adanya video camera, banyaknya perangkat komputer yang rusak,akses komputer kurang cepat dan kurang tepat, seperti jasa chating yang kurang cepat atau lamban,ruangan komputer kurang memadahi dan kurang nyaman hal ini dapat dilihat pada ruangan yang terkesan kotor dan tidak adanya tempat sampah di dalam ruangan, tempat parkir yang memadahi dan nyaman, ketelitian pegawai dalam memberi pelayanan masih kurang, kemampuan petugas dalam memberi informasi yang jelas, kemudahan dalam mendapatkan informasi,jaminan keamanan dalam menggunakan jasa.

\section{Kesimpulan}

Kesimpulan yang dapat ditarik dari analisis diatas adalah :

1).Secara umum tingkat kepuasan pelanggan jasa iternet belum merasa puas.

2).Pelayanan yang diberikan oleh perusahaan jasa internet sebagian besar telah berhasil memberikan pelayanan terbaiknya, oleh karena itu perlu dipertahankan dan ditingkatkan lagi, hal ini dapat dilihat pada kuadran B, namun masih ada beberapa item yang berada pada kuadran A, hal ini menunjukkan bahwa pelanggan jasa internet belum merasa puas terhadap beberapa item yang ada.

\section{Saran}

1). Bagi peneliti lanjutan, simpulan diatas memberikan bukti empiris yang bisa digunakan sebagai pijakan gagasan kearah penelitian yang lebih mendalam tentang kualitas pelayanan mengingat kepuasan pelanggan jasa internet belum merasa puas. Akan lebih menarik bila dipertimbangkan varaiabel lain seperti kemampuan uji (testability), kemampuan intra operasi /LAN

2). Bagi Pimpinan Perusahaan kiranya bukti ini dijadikan bahan masukan untuk menentukan strategi pemasaran efektif bagaimana dalam menjaring calon pelanggan. 


\section{DAFTAR PUSTAKA}

Cronin,Joseph J,and S.A Taylor (1993): Measuring Srvice Quality:Reexmination and Extension, Journal of Marketing July (vol.56) p.55-68.

Http:/ /www.geocities.com/yazma-2000/ami.hdml.

Gaspersz,Vincent,1997 : Manajemen Kualitas dalam Industri Jasa, PT Gramedia Pustaka Utama, Jakarta.

Indriantoro N,Supomo,1999, Metodologi Penelitian Bisnis, Cetakan Pertama, Penerbit BPFE Yogyakarta.

Kotler,Philip,1997: Manajemen Pemasaran : Analisis Perencanaan Implementasi dan Pengendalian, Salemba Empat, Jakarta.

Kotler,Philip, Gary Amstrong, 1996: Dasar-Dasar Pemasaran Jilid 2,Alih bahasa Alexander Sindoro, Prenhallindo, Jakarta.

Kuncoro,Mudrajad, 2003 : Metode Riset untuk Bisnis E Ekonomi, Penerbit Erlangga,Jakarta.

Lupiyoadi,Rambat,2001 : Manajemen Pemasaran Jasa, Penerbit Salemba Empat, Jakarta.

Pujawan, Tetra,1997: Analisis Faktor-faktor Kualitas Layanan yang Mempengaruhi Kepuasan Pelanggan Bank, Tesis Universitas Brawijaya, Malang.

Rismiati, Catur E, dan Bondan Suratno, 2001: Pemasaran Barang dan Jasa,_Penerbit Kanisius, Yogyakarta.

Santoso, Singgih, 2001. SPSS Statistik Parametrik, Cetakan kedua, Penerbit PT Elex Media Komputindo, Jakarta.

Supranto J, 1997. Pengukuran Tingkat Kepuasan Pelanggan, Cetakan pertama, Penerbit Rineka Cipta, Jakarta.

SWA, edisi 7 - 27 Maret 1996

SWA, edisi 5-18 September 2002

Umar Husein, 2000: Riset Pemasaran E Perilaku Konsumen, Penerbit PT Gramedia Pustaka Utama, Jakarta. 
Warta Ekonomi, No.05/XV/12 edisi Maret 2003.

*) Drs. Joko Samboro, Staf Pengajar Politeknik Negeri Malang Jurusan Administrasi Bisnis 
